\title{
GRACE: O'MALLey MeETS THE ENGLISH QUEEN (1593)
}

\author{
Heidi Czerwiec
}

Gracelessly, I shaved my hair when informed that, as a girl, I could not man my father's fleets along the Irish Atlantic.

And if man, why not chieftain? Why not take and tack those ships, claim them name them mine?

And if I am a Pirate King (or Queen), why should I not consort with one of my own, another island queen with navy alike?

Without grace

her smirking guards at Greenwich frisked me, found my girdled dirk. Yet at this, the Queen grinned, said As equals then, in Latin, let us speak. A woman needs about her her own prick if we are to navigate this world of men with grace. 